\title{
Simulation Based Energy-resource Efficient Manufacturing Integrated with In-process Virtual Management
}

\author{
KATCHASUWANMANEE Kanet ${ }^{1}$, CHENG Kai ${ }^{1, *}$, and BATEMAN Richard ${ }^{2}$ \\ 1 College of Engineering, Design and Physical Sciences, Brunel University, London UB8 3PH, UK \\ 2 Faculty of Engineering, Environment and Computing, Coventry University, Coventry CV1 5FB, UK
}

Received May 24, 2016; revised June 21, 2016; accepted July 14, 2016

\begin{abstract}
As energy efficiency is one of the key essentials towards sustainability, the development of an energy-resource efficient manufacturing system is among the great challenges facing the current industry. Meanwhile, the availability of advanced technological innovation has created more complex manufacturing systems that involve a large variety of processes and machines serving different functions. To extend the limited knowledge on energy-efficient scheduling, the research presented in this paper attempts to model the production schedule at an operation process by considering the balance of energy consumption reduction in production, production work flow (productivity) and quality. An innovative systematic approach to manufacturing energy-resource efficiency is proposed with the virtual simulation as a predictive modelling enabler, which provides real-time manufacturing monitoring, virtual displays and decision-makings and consequentially an analytical and multidimensional correlation analysis on interdependent relationships among energy consumption, work flow and quality errors. The regression analysis results demonstrate positive relationships between the work flow and quality errors and the work flow and energy consumption. When production scheduling is controlled through optimization of work flow, quality errors and overall energy consumption, the energy-resource efficiency can be achieved in the production. Together, this proposed multidimensional modelling and analysis approach provides optimal conditions for the production scheduling at the manufacturing system by taking account of production quality, energy consumption and resource efficiency, which can lead to the key competitive advantages and sustainability of the system operations in the industry.
\end{abstract}

Keywords: energy-resource efficient manufacturing, virtual manufacturing, manufacturing simulation, in-process virtual management

\section{Introduction}

Energy and resource efficiency in manufacturing has received considerable attention in sustainable manufacturing research and development ${ }^{[1]}$. These growing trends have responded to the emerging concerns in environmental issues such as declining non-renewable energy resources as well as increasingly stringent legislations and requirements for manufacturers and even higher consumer demand for environmentally friendly products $^{[2-3]}$. The escalating demand for energy together with scarcity of energy resources have resulted in high costs of energy and simultaneously in a destructive impact on the ecosystems due to fossil fuels being the main sources of the overall world energy consumption. Taken together, environments, economic and society all have valuable contributions towards energy efficiency in the modern manufacturing industry ${ }^{[4]}$. Manufacturers are therefore facing great challenges, and one important way to gain competitive advantages is to deliver energy and

\footnotetext{
* Corresponding author. E-mail: kai.cheng@brunel.ac.uk

Supported by the EU 7th Framework ICT Programme under EuroEnergest Project (Contract No. 288102)

(C) Chinese Mechanical Engineering Society and Springer-Verlag Berlin Heidelberg 2016
}

resource efficient performance through optimal manufacturing processes ${ }^{[5]}$. In essence, the development of efficient manufacturing systems towards sustainability cannot specifically focus on an individual level, but instead they need to acknowledge and consider all applicable levels namely product, process, and system ${ }^{[6]}$.

Particularly, at the operational level of the production processes, scheduling is a significant source of impact on the cost, quality and efficiency of the production which are the three essential components towards sustainable manufacturing ${ }^{[7]}$. Variations in operations scheduling can have consequences on the emissions and resource consumption. Despite an increase of studies in the areas of scheduling, researchers can advance the existing knowledge by considering both academic and industrial needs through various methodological and strategical models ${ }^{[6]}$. Relatedly, studies on scheduling in relation to sustainability, especially on how operations scheduling can maximally reduce environmental impacts, are still limited ${ }^{[8-9]}$. The majority of existing studies have focused on energy savings from a single resource. The present paper attempts to advance the existing research on scheduling so as to lead to better management of energy consumption and production quality of the manufacturing 
system without compromising of the system productivity. In particular, it extends previous findings by investigating on a more complex manufacturing system reality in a multidimensional manner, which is becoming increasingly relevant to the future manufacturing industry.

\section{Energy Efficiency in Sustainable Manufacturing}

An accurate and thorough analysis of energy consumption behavior is rather requisite to the success of energy efficiency approaches ${ }^{[10]}$. Respecting production of energy, the utmost importance concerns a thorough analysis of the production equipment namely the machines. It has been established in research that different forms of energy consumption (e.g., electricity, compressed air and process gas) are dynamic which is altered according to the status of the machine and the production process ${ }^{[11]}$. This assumption is also applied regardless of the diverse types of production machines.

Broadly, the energy profile of a particular machine is composed of different energy-consuming parts. Fig. 1 presents an example of the energy profile of a grinding machine ${ }^{[10]}$. More specifically, energy profiles consist of energy that consumes at constant and variable rates ${ }^{[12]}$. The energy consumption that is constant is typically related to machine parts that implement an operating state such as pumps, coolers and control units. On the other hand, the variable energy consumption encompasses the electrical energy that is required for the actual operations or tool positioning and handling. Therefore, constant energy consumption contributes to a large amount of the total energy consumption depending on the feature and the type of the machine along with its application. Overall, the energy profile can provide critical application on the information of the machine components and the source of measure of the energy efficient optimization for a specific, individual machine such as the energy consumption for electric motors in a modified production process ${ }^{[13]}$. The following sections review two essential perspectives within the production stage which are peak power consumption and overall energy consumption ${ }^{[14]}$.

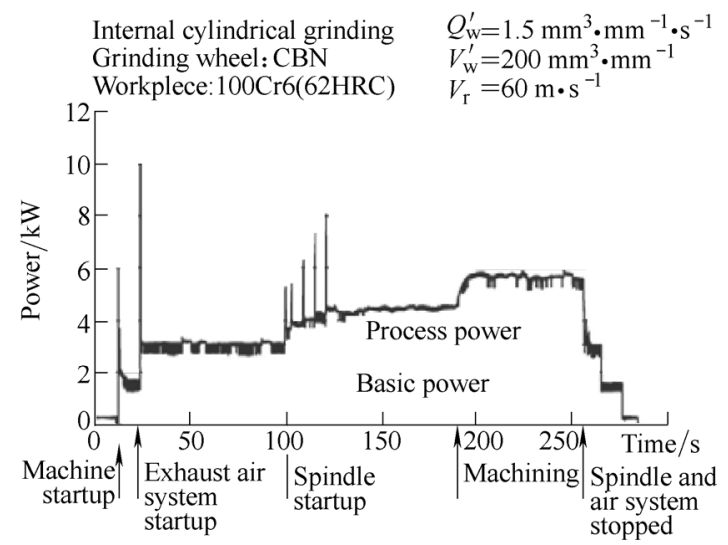

Fig. 1. Example of an energy profile of a production machine

\subsection{Avoiding peak power consumption}

To manage peak power consumption, the system commonly focuses on strategical processes designed to avoid or minimize energy consumption at the peak load ${ }^{[14]}$. For instance, BABU, et $\mathrm{al}^{[15]}$, introduced an optimization formulation by implementing a mixed integer nonlinear programming (or MINLP) to schedule the manufacturing loads and thus avoid the energy peak demand. Likewise, in a study of $\mathrm{FANG}$, et $\mathrm{al}^{[8]}$, a multi-objective mixed integer programming model was developed to optimize the schedule of a flowshop by varying on operations speed to reduce peak power load. NGHIEM, et $\mathrm{al}^{[16]}$, introduced an algorithmic system that incorporated a peak power consumption of a hybrid automaton during the real-time scheduling process that was implemented to create a model of the control system. In addition, BRUZZONNE, et $\mathrm{al}^{[17]}$, conducted an experiment of a two-step operational method to calculate the peak power consumption in flexible flowshops by which the first step focused on a planning and scheduling system in isolation of the energy consumption. Second, the following step was to perform a mixed integer programming (MIP) which aimed to increase the energy consumption without modifying the scheduling sequence. Nevertheless, the methods of avoiding peak power consumption only focus on the systems whereby the available energy and energy peaks are limited. Whilst this approach provides advantages towards sustainability, it is, however, outside the scope of the present paper.

\subsection{Reducing the overall energy consumption}

Another, possibly more prevalent, approach focuses on reduction of the overall energy consumption. In sustainable manufacturing literature, three solutions or approaches within the production system have been proposed and modelled. Fig. 2 illustrates these approaches and their relations to the broader manufacturing energy efficiency perspective $^{[14]}$.

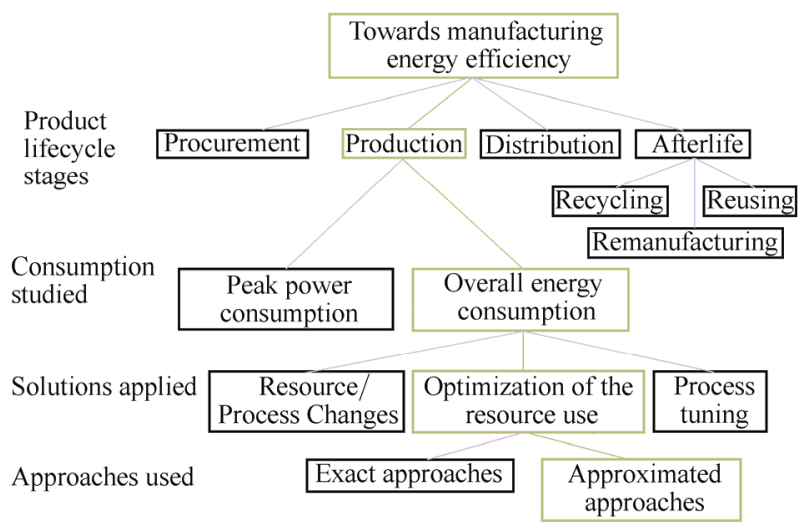

Fig. 2. Three approaches of overall energy consumption in energy efficiency

\subsubsection{Resources/process changes}

Among the three solutions, changing the resource or the process is regarded as the traditional, or probably the simplest, approach towards energy efficiency in 
manufacturing $^{[14]}$. As the study of KARNOUSKOS, et al ${ }^{[18]}$ showed, the resources could automatically manage the energy consumption of the integrated energy monitoring system in the overall manufacturing system, such as embedded devices, resource planning and logic controller. These resources were found to reduce energy consumption if the task was not being performed on these resources. In addition to these results, the operations process was able to change due to the result of the change in the resource in an accurate manner.

\subsubsection{Process tuning}

Because adapting new resources or processes can require a large investment and extensive changes of the broader manufacturing system, another approach in reducing energy consumption focuses on modification and optimization of the existing resource or process (i.e., process tuning) ${ }^{[1,14]}$. This approach can be less costly and is less likely to involve radical changes. One example is the experiment conducted by MORI, et al ${ }^{[19]}$ which examined a decrease in energy usage through modification of cutting conditions of machine tools, adaptive pecking cycle and synchronization of the spindle speed.

Relatedly, BI, et $\mathrm{al}^{[20]}$, developed the energy model of the Exechon machine tool. The results showed that through optimization of the machine setup, this strategy could reduce $67 \%$ of energy for the drilling operations which was approximately $31 \%$ of the average energy consumption of the initial setup. These studies have provided experimental evidence to support process tuning as one of the effective approaches in sustainable manufacturing. By modifying specific process parameters such as speed, depth, feed rate, forces and temperature, the overall energy consumption of the manufacturing system can be, to varying degrees, reduced. While this approach is beneficial for energy efficient system, the performance of optimization may lessen quality objectives ${ }^{[21]}$ and shorten resource lifespan $^{[14]}$.

\subsubsection{Optimization of resource use}

Considering the potential drawbacks of the previous approaches, this last approach concerns optimization of the resource use. While existing resource and processes stay consistent, the modification is applied to the scheduling and control systems ${ }^{[14]}$. In general, an overall increase in energy can be significantly high. For instance, DEVOLDERE, et $\mathrm{al}^{[22]}$, examined on the energy consumption of a milling machine and a 50-ton machine, and the resulted showed that approximately, respectively, $47 \%$ and $65 \%$ of the energy consumption were accounted by the non-production function. This study provided evidence for energy reduction through optimization of resource use.

In general, there are two common methods within this strategy namely exact and approximated. First, the exact methods generally manage energy-related factors with fixed conditions. MATI, et $\mathrm{al}^{[23]}$, addressed the scheduling problem of the two-job shop with machines of various purposes known as NP-hard (i.e., non-deterministic polynomial-time hard) by which the processing and completion times tend to be significantly long. An attempt to reduce energy consumption in the manufacturing system with NP-hard would complicate or even constrain the process further. Consistently, VALLADA, et $\mathrm{al}^{[24]}$, explained that the exact methods could be impracticable for complex flowshop that involves high-volume operations. Exact methods are also problematic and less likely to be suited for the manufacturing environments with frequently disrupted operations or dynamic changes ${ }^{[25]}$.

More recent researchers have thus paid attention to approximated methods which can be broadly classified into heuristics, metaheuristics and distributed or multi-agents, and have been described as effective methods especially for a manufacturing system with a large number of machines ${ }^{[24,26-27]}$. These methods, especially heuristics and meta-heuristics, are considered as centralized predictive methods because they involve shorter completion time than the exact methods. Rather than undertaking the optimal solutions, these methods provide better solutions within a reasonable timeframe. For instance, KUSTER, et $\mathrm{al}^{[28]}$, highlighted on the control approach based on a strategy through optimization of production schedules regarding predictions of day-ahead energy prices. The optimization emphasized on the importance of the scheduling process and its management in the design of the energy efficient production systems.

\section{Resource Efficient Scheduling Based on Energy Demand}

A variety of production processes constitute a production system which comprises of different, and typically of various purposes (e.g., personnel, processing and transportation), machines. To achieve an optimal performance, the production management plans and controls the different functions of production by considering the related technical machines. The machines provide profiles of energy consumption in load curves that are cumulated during the production process. In order to conserve energy, an inactive resource should turn off the operations of the power supply when there is no relevant production nearby the resource within the time slot. Reversely, the resource needs to switch on the power supply when the product appears to be near the resource. Nonetheless, the resource needs knowledge about the relevant products in order to make the consumption behavior consistent.

In this research, the model manages energy efficiency with the total energy consumption and manages effectiveness with time spent for each resource in order to assemble the product in various conditions or scenarios. The energy consumption of the system is analyzed from the subsequent formulas ${ }^{[14]}$. First, the energy consumption, 
which is expressed as $W_{(r, i)}$, where $r$ is the resource and $i$ is its specific state, is equal to the time production integral of the power by which $T_{\text {prod }}$ expresses time production and $P_{r, i}(t)$ expresses power. This equation is written as:

$$
W_{(r, i)}=\int_{0}^{T_{\text {prod }}} P_{(r, i)}(t) \mathrm{d} t .
$$

Following the previous denotations, the total consumption or $T W_{r}$ of a resource equates the sum of the energy consumption in all states. Where $N$ determines the number of states, the formula for the total consumption is written as:

$$
T W_{r}=\sum_{i=1}^{N} W_{r, i}
$$

Last, the overall energy consumption of the system, expressed as $T R$, is the sum of the total consumption of all resources. Where $R$ determines the number of resources, the formula can be written as:

$$
T R=\sum_{r=1}^{R} T W_{r}
$$

\section{Virtual Simulation of Energy-resource Efficient}

The present experiment follows the virtual simulation approach which demonstrates a realistic model of the production system that captures energy and resource efficient performance. The virtual simulation presents the interdependent relationships along with their dynamics of the full equipment to efficiently facilitate design and control processes of the production system. Accordingly, this approach is not intended to exhibit the operations of an individual machine or a particular manufacturing process. Instead, it integrally considers multiple functions (e.g., quantity, time and availability of the manufacturing system) in relation to the energy consumption directions by which energy-related flows, both input and output are evaluated altogether. The structure of this approach is generally presented in levels which are input, logic, user and evaluation $^{[10]}$.

Another essential feature of this simulation approach is the adjustable process modules that can enhance applicability by reducing knowledge modeling and modeling efforts. The adjustment of process modules can be performed within given parameters by using accessible data. Respectively, the modules enable the simulation to demonstrate the key performance of the manufacturing process. The level of details, therefore, can be adapted depending upon the objective of the analysis. When background data are included, it may be necessary to augment minor processes into a single process module. More importantly, the energy consumption pattern can be incorporated within each process module.
More specifically to this research, the virtual simulation system provides the virtual-friendly, real-time manufacturing presentation and facilitates real-time decision making in a systematically precise manner as possible. As illustrated in Fig. 3, this predictive simulation system acquires data (e.g., production process and scheduling data) from the factory and large manufacturing and also presents an analysis of the multi-dimensional correlation between the EWQ flows (i.e., energy flow, work flow and quality flow) in the shop floor ${ }^{[29]}$. Both data and analytical correlation comprehensively implement the performance of this virtual simulation of energy-resource efficient. The understanding of the present simulation will advance the control system development and eventually the development of optimization to better reduce energy usage.

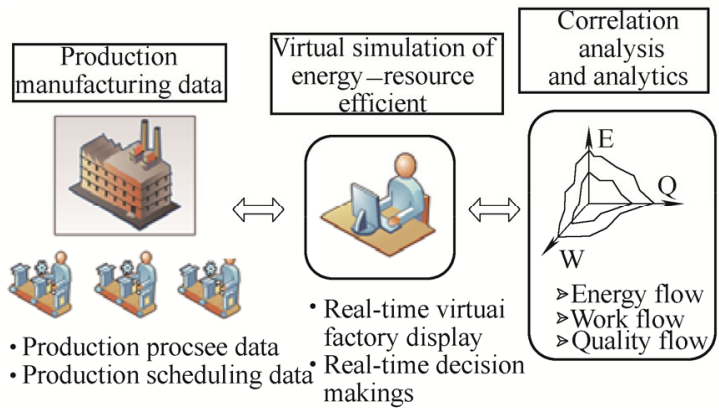

Fig. 3. Architecture of the energy-resource efficient virtual simulation

As described above, a systematic approach is necessary in the development of a modelling of an industrial application in order to cover the complete aspects of the system and to successfully implement the source and prioritization of strategies. To achieve this, the experiment adopts a three-step improvement method as follows.

Step 1: Production processes and schedules.

The crucial task during this first step is to analyze the distinguishing mechanical and organizational features that are applicable to the processes of the production system. By including relevant information on manufacturing machines and management such as planning, material flows and cycle times, this analysis should provide a better understanding on the production system and its data that are necessary for the consequent steps.

Step 2: Energy analysis and production.

This second step, energy analysis and production, focuses on a more thorough and in-depth analysis by considering both input and output flows of the production machines. Therefore, it is important to analyze not only the entire process model but also to examine all the related energy input and output of the machines. First, the technical documents should be reviewed as they can be used to prioritize processes as they include basic data on energy consumption. Because the values in these data tend to be higher than the actual values, actual energy measurements are then determined for energy profiles of, at least, major manufacturing processes. 
Step 3: Integrated simulation and evaluation of production systems.

In this last step, aspects of the entire production system along with its process chains enable the technical interdependencies among various machines and the outcomes of technical and organizational measures. The virtual simulation of this experiment is essential to manage the problem dynamics by which the data are accumulated and result in the comprehensive load curve for the complete system.

\section{Implementation and Optimization}

This experiment was established in the Brunel University Advanced Manufacturing Laboratory which was suitable to the present methodological approach as the laboratory comprised of the entire area of the machine work and its environment. The experimentation consisted of 20 aluminum tests which were performed on the $\mathrm{CNC}$ machine with variations of workloads. The virtual simulation programme was used to model the production at the applicable level of details. More specifically, a LabVIEW programme was run to display the real-time virtual simulation of energy and resource efficient. The virtual simulation consisted of 5 main panels which were real-time virtual simulation, Arena Simulation in manufacturing production process, overall machine utilization, production energy consumption and product quality as shown in Fig. 4. The virtual simulation development is a part of research efforts in developing energy-resource efficient factory of the future, combining the in-process analysis, analytics and real-time manufacturing decision-makings with the advanced ICT techniques $^{[32]}$.

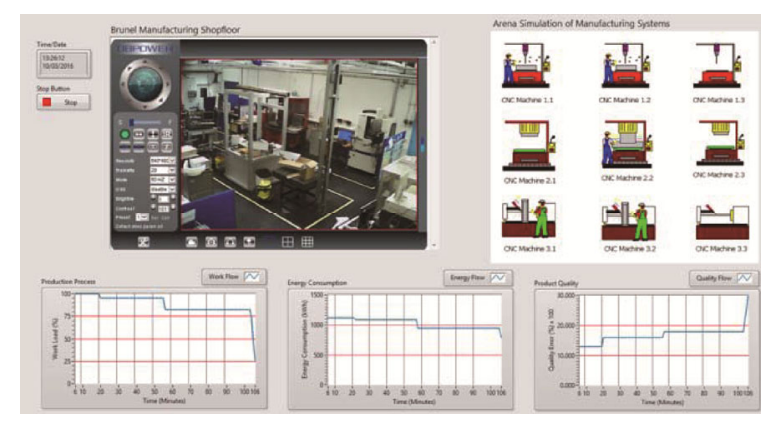

Fig. 4. Energy-resource efficient virtual simulation

\subsection{Production processes and scheduling}

The production system and scheduling simulation, as shown in the top right of Fig. 4, were displayed to monitor and utilize resources of the simulated model. The model was simulated by using Arena Simulation programme. In this simulation, the work flow changed during the period of time due to the scheduling of production line. There were three processes and three production lines in this automated simulation including $9 \mathrm{CNC}$ machines. The machine status consisted of machine turn on, machine turn off and machine idle.

\subsection{Energy measurement}

To measure energy consumption, a 'Power logger' hardware was selected as it can establish a high level of precision measurement ${ }^{[30]}$. The Fluke 1735 power logger was specifically used to measure three phases of the power supplied in order to collect data on the total energy consumption of the processes. The measurement results were directly linked to the virtual simulation.

\subsection{Accuracy measurement}

Machining errors were then measured after the experiments of machining. The measurements were performed with a Coordinate Measuring Machine or CMM, namely MITUTOYO FN503. Since the working environment is the important factor that can fluctuate accuracy of the $\mathrm{CMM}^{[31]}$, this specific measuring machine was placed in the laboratory in which the temperature was set and controlled at $20^{\circ} \mathrm{C}$. Probing was carried out on the fixture of the aluminum workpieces. Machining error was calculated as the difference between the reference points in the probe deviations. Particularly, a total of 14 varied dimensions of measurement of machining error were included with 9 length and 5 depth errors and were performed on the reference points. Once the CMM code was programmed, the process was automated through a NC program on a CAD systems and operations on the measurement process on each of the 20 workpieces of aluminum. The test sheets were then created for examination and further analysis.

\section{Results and Discussion}

The collected data from the milling aluminum tests were analysed which resulted in a correlational graph of work flow about the overall energy consumption generated from the simulation as depicted in Fig. 5. The results showed that, in the work flow that ranged between $25 \%$ and $100 \%$, a correlational relationship between work flow and energy consumption was positive, indicating a raise of energy consumption while work flow was increasing. Specifically, at $25 \%$ work flow, the system generated approximately 265 $\mathrm{kW}$ of energy in order to finish the processes. At $100 \%$ work flow, the machining systems then approximately generated an increasing amount of $1173 \mathrm{~kW}$ of energy. The correlation of work flow and energy consumption is described in Eq. (4):

$$
y_{1}=12.105 x_{1}-37.152
$$

where $x_{1}$ is work flow and $y_{1}$ is energy consumption.

Next, a positive correlation was established between work flow and product quality measured by percentages of quality errors, shown in Fig. 5. Specifically, when work 
flow was at $25 \%$, the product quality error was estimated to be at approximately $0.0475 \%$. However, the quality errors increased to $0.1610 \%$ when the system was being fully operated. The correlational equation of work flow and quality error is described by Eq. (5):

$$
y_{2}=0.1513 x_{2}+0.9719 \text {, }
$$

where $x_{2}$ is work flow and $y_{2}$ is quality error.

In addition, the correlation of both regression lines in Fig. 5 was shown to be positive, suggesting that more energy was being consumed and, simultaneously, more quality errors of products occurred at higher work flows. As a result of the two regression lines, the intersection was obtained at $75 \%$ of work flow. At this intersection point, the energy consumption was at $870 \mathrm{~kW}$ with the quality error of $0.215935 \%$.

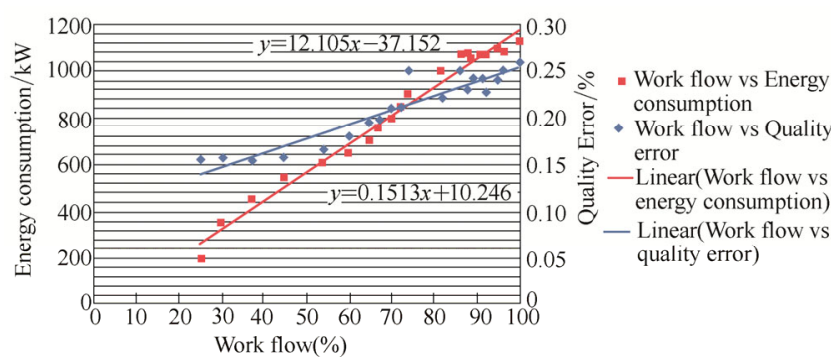

Fig. 5. Work flow and energy consumption versus quality error

As shown in Fig. 6, the 3D correlation between the 3 flows which were work flow, energy consumption, and quality error was generated by the simulating Matlab and SigmaPlot programme. The multidimensional correlation of work flow, energy consumption and quality error can be summarized by Eq. (6):

$$
z=-0.0017 x-0.0006 y+0.9719 \text {, }
$$

where $x$ is work flow, $y$ is energy consumption, and $z$ is quality error.

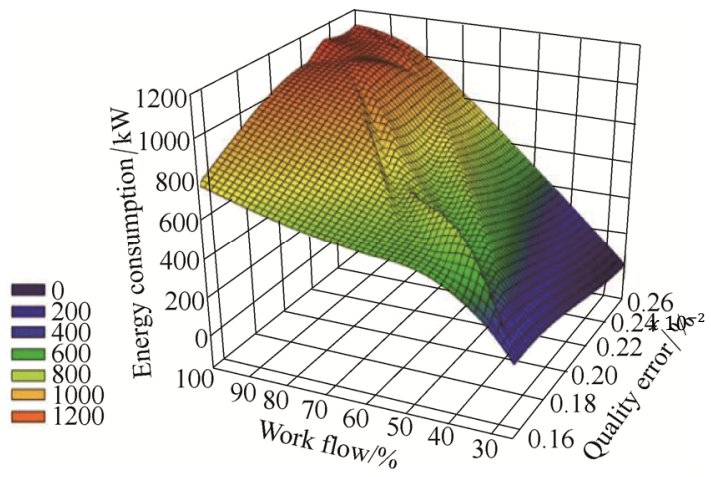

Fig. 6. 3D correlational analysis of energy

Consumption, work flow and quality error based on this experiment, work flow in the production scheduling process should be controlled and optimized in order to optimally obtain the improved product quality together with minimizing the over energy consumption. This research identified optimization of work flow as the crucial factor that can facilitate the reduction of energy consumption and also maintain the quality of the product. The findings suggested that $75 \%$ of work flow appears to be the optimal parameter for energy efficiency in a means of overall energy consumption when product quality is also achieved. Evaluating all potential factors to gain predictive energy consumption and machining error can be a complicated task. Nevertheless, this research highlighted the role of production scheduling as the key factor that influences energy consumption and also the quality error of product in the manufacturing system.

\section{Conclusions}

In response to the issues linking to environmental concerns, a high rise in energy costs, stringent regulations and legislations, and changing preferences of consumer demands over the last decade or so, the majority of the manufacturers are increasingly moving towards sustainable manufacturing while at the same time need to gain competitive advantages and maintaining the production productivity and quality. The present research was carried out to model operations scheduling in the manufacturing system by optimizing work flow of the production processes in order to determine underlying relationships among the energy consumption, production quality and productivity flow. The virtual simulation approach was undertaken to design and present real-time manufacturing monitoring, virtual displays and responsive decision makings with the three dimensional correlation analysis in order to evaluate the energy consumption and quality error scheduling of the production system. With the three-step methodological approach, the simulation model provided technical evaluation on the scheduling process of the production system.

The results of the analysis highlighted the importance of including effectiveness, which was indicated by quality error and efficiency, which was determined by energy consumption, criteria in a dynamic manufacturing system. Overall, the correlations between the work flow and energy consumption and the work flow and quality error are positive, suggesting that at high work flow, a great amount of energy is consumed and product quality is lowered. More importantly, the present research supports the effective scheduling process in manufacturing system where it needs to be controlled and managed accordingly in order to enhance energy efficiency and achieve the set level of product quality. The present virtual simulation further provides a systematical approach for production management particularly towards energy and resource efficient manufacturing at a manufacturing system.

\section{References}

[1] DUFLOU J R, SUTHERLAND J W, DORNFIELD D, et al. 
Towards energy and resource efficient manufacturing: A processes and systems approach[J]. CIRP Annal-Manufacturing Technology, 2012, 61: 587-609.

[2] ALLWOOD J M, CULLEN J M. Sustainable materials: With both eyes open[M]. UIT Cambridge, Cambridge, 2012.

[3] BEY N, HAUSCHILD M Z, MCALOONE T C. Drivers and barriers for implementation of environmental strategies in manufacturing companies[J]. CIRP Annals-Manufacturing Technology, 2013, 62: 43-46.

[4] GERETTI M, TAISCH M. Sustainable manufacturing: Trends and research challenges[J]. Production Planning \& Control: The Management of Operations, 2012, 23: 83-104.

[5] RENTSCH R, HEINZEL C, BRINKSMEIER E. Artificial intelligence for an energy and resource efficient manufacturing chain design and operation[J]. Procedia CIRP, 2015, 33: 139-144.

[6] GIRET A, TRENTESAUX D, PRABHU V. Sustainability in manufacturing operations scheduling: A state of the art review[J]. Journal of Manufacturing Systems, 2015, 37: 126-140.

[7] TRENTESAUX D, PRABHU V. Sustainability in manufacturing operations scheduling: stakes, approaches and trends[M]//GRABOT B, VALLESPIR B, GOMES S, et al eds. Adv Prod Manage SystInnovKnowl Based Prod Manage Glob—Local World. Springer, Heidelberg, 2014: 106-113.

[8] FANG K, UHAN N, ZHAO F, et al. A new approach to scheduling in manufacturing for power consumption and carbon footprint reduction[J]. Journal of Manufacturing Systems, 2011, 30: 234-240.

[9] PRABHU V V, JEON H W, TAISCH M. Simulation modelling of energy dynamics in discrete manufacturing systems[M]//Service orientation in holonic and multi agent manufacturing and robotics, Springer, Heidelberg, 2013

[10] HERRMANN C, THIEDE S. Process chain simulation to foster energy efficiency in manufacturing[J]. CIRP-Journal of ManufacturingScience and Technology, 2009, 1: 221-229.

[11] THIEDE S. Energy efficiency in manufacturing systems[M]. Springer, Heidelberg, 2012

[12] GUTOWSKI T, DAHMUS J, THIRIEZ A. Electrical Energy Requirements for Manufacturing Processes[C]//Proceedings of 13th CIRP International Conference on Life Cycle Engineering, Leuven, Belgium, May 31-June 2, 2006, 31: 623-638.

[13] DEVOLDERE T, DEWULF W, DEPREZ W, et al. Improvement potential for energy consumption in discretepart production machines[C]//Proceedings of the 14th CIRP Conference on Life Cycle Engineering,Tokyo, Japan, 2007: 311-316.

[14] PACH C, BERGER T, SALLEZ Y, et al. Reactive and energy-aware scheduling of flexible manufacturing systems using potential fields[J]. Computers in Industry, 2014, 65: 434-448.

[15] BABU CA, ASHOK S. Peak load management in electrolytic process industries[J]. IEEE Transactions on Power Systems, 2008, 23: 399-405.

[16] NGHIEM T, BEHL M, PAPPAS G J, et al. Green scheduling: Scheduling of control systems for peak power reduction[C]//Green Computing Conference and Workshops (IGCC) International, 2011: $1-8$.

[17] BRUZZONE A A G, ANGHINOLFI D, PAOLUCCI M. Energy-aware scheduling for improving manufacturing process sustainability: A mathematical model for flexible flow shops[J]. CIRP Annals-Manufacturing Technology, 2012, 61: 459-462.

[18] KARNOUSKOS S, COLUMBO A W, LASTRA J L M, et al. Towards the energy efficient future energy $[\mathrm{C}] / / 7$ th IEEE International Conference on Industrial Informatics INDIN, 2009: 367-371.

[19] MORI M, FUJISHIMA M, INAMASU Y, et al. A study on energy efficiency improvement for machine tools[J]. CIRP AnnalsManufacturing Technology, 2011, 60: 145-148.

[20] BI ZM, WANG, L. Optimization of machining processes from the perspective of energy consumption: A case study[J]. Journal of
Manufacturing Systems, 2012, 31: 420-428.

[21] WANG Q, LIU F, WANG X. Multi-objective optimization of machining parameters considering energy consumption[J]. International Journal of Advance Manufacturing Technology, 2014, 71: 1133-1142.

[22] DEVOLDERE T, DEWULF W, DEPREZ W, et al. Improvement potential for energy consumption in discrete part production machines[M]//Advances in life cycle engineering for sustainable manufacturing businesses. Springer, London, 2007.

[23] MATI Y, XIE X. A polynomial algorithm for a two-job shop scheduling problem with routing flexibility $[\mathrm{C}] / /$ Robotics and automation Proceedings ICRA03 IEEE International Conference, 2003, 1: 157-162.

[24] VALLADA E, RUIZ R, MINELLA G. Minimising total tardiness in the m-machine flowshop problem: A review and evaluation of heuristics and metaheuristics[J]. Computers \& Operations Research, 2008, 35: 1350-1373.

[25] MARIK V, MCFARLANE D. Industrial adoption of agent-based technologies[J]. IEEE Intelligent Systems, 2005, 1: 27-35.

[26] LEE J H, KIM C O. Multi-agent systems applications in manufacturing systems and supply chain management: A review paper[J]. International Journal of Production Research, 2008, 46: 233-265.

[27] SHEN W, HAO Q, YOON H J, et al. Applications of agent-based systems in intelligent manufacturing: An updated review[J]. Advanced Engineering Informatics, 2006, 20: 415-431.

[28] KUSTER T, LUTZENBERGER M, FREUND D, et al. Distributed optimization of energy costs in manufacturing using multi-agent system technology[C]//Proceedings of the 2nd International Conference on Smart Grids Green Communications and IT Energy-aware Technologies, Maho Beach, St. Maarten, 2012.

[29] KATCHASUWANMANEE, K, BATEMAN R, CHENG K. Development of theenergy-smartproductionmanagementsystem (e-ProMan): A big data drivenapproachanalysis and optimization[J]. Proceedings of the Institution of Mechanical Engineers, Part B: Journal of Engineering Manufacture, 2015, 230(5): 972-978.

[30] NOUREDDINE A, ROUVOY R, SEINTURIER L. A review of energy measurement approaches[J]. ACM SIGOPS Operating Systems Review, 2013, 47: 42-49.

[31] LEACH R. Fundamental principles of engineering nanometrology [M]. Elsevier, Philadelphia, PA, 2014.

[32] CHENG K, BATEMANR J. e-Manufacturing: characteristics, applications and potentials[J]. Progress in Natural Science, 2008, 18: $1323-1328$

\section{Biographical notes}

KATCHASUWANMANEE Kanet is currently a $\mathrm{PhD}$ candidate in manufacturing engineering at Brunel University, London, UK. His research interests include energy efficiency and energy management in manufacturing system.

E-mail: kanet.katchasuwanmanee@brunel.ac.uk

CHENG Kai is currently a professor of manufacturing engineering at Brunel University, London, UK. His main research interests include design of high precision machines, ultraprecision and micro machining, multiscale multi-physics based design and analysis, smart tooling and smart machining and sustainable manufacturing systems.

E-mail: kai.cheng@brunel.ac.uk

BATEMAN Richard is currently a senior lecturer at Coventry University, Coventry, UK. His main research interests include energy efficient \& energy smart manufacturing and digital manufacturing.

E-mail: richard.bateman@coventry.ac.uk 